\title{
Overview and management of toxicities of immune checkpoint-blocking drugs
}

\author{
Panagiota Economopoulou*, Amanda Psyrri \\ University General Hospital ATHENS , GREECE
}

Received 27 May 2016; Accepted 30 May 2016

\begin{abstract}
Immunotherapy is considered to be the most important breakthrough in cancer management in the past few years. This success was based on the scientific understanding of immune mechanisms due to improvement in preclinical science and the introduction of new methods of investigation. Immune checkpoint inhibitors (ICls) are among the most promising drugs in the field of immune-oncology; they represent monoclonal antibodies that modulate the effects of immune checkpoints, such as cytotoxic $T$ lymphocyte Antigen 4 (CTLA-4) and Programmed Cell Death protein 1 (PD-1), which are co-inhibitory signals responsible for immune suppression. Despite clinical benefits, ICls are immune activating agents that are associated with a number of important side effects (immune-related adverse events-irAEs), attributed to organ-specific inflammation. Herein, we review the toxicities of ICls, highlighting the importance of early identification and management.
\end{abstract}

Keywords: Immune checkpoint inhibitors •Immunotherapy • Toxicity・Immune-related adverse events

(C) De Gruyter Open

\section{Introduction}

Emerging evidence supports a vital role of the endogenous immune response system in the recognition, control and elimination of malignant cells. In the early phases of cancer development, molecular alterations caused by the tumour trigger the development of tumour-associated antigens (TAAs), which are initially recognised by the immune system. During tumour evolution, accumulation of genetic mutations or specific selection of tumour cells that escape immune response lead to immune evasion or disruption. The delicate equilibrium between co-stimulatory and co-inhibitory signals, which normally regulates immune response and prevents autoimmunity, is deranged by the cancer cell to escape immune surveillance (1-2).

Among co-inhibitory signals, immune checkpoints represent immunological breaks that repress activating effects in order to avoid unchecked self-destruction of normal tissues (3). Cytotoxic T lymphocyte Antigen 4 (CTLA-4) and Programmed Cell Death protein 1 (PD-1) are the two main inhibitory checkpoint pathways involved. CTLA-4 exerts its effects when it is expressed on the surface of CD4+ and CD8+ lymphocytes. It blocks T cell activation by competing co-stimulatory receptor CD28 for its $B 7$ ligands, CD80 and CD86, which are present on antigen-presenting cells (APCs) (4). Blockade of CTLA-4 using CTLA-4 monoclonal antibodies such as ipilimumab and tremelimumab releases CD28, which binds to B7 ligands to produce a stimulatory signal.

$\mathrm{PD}-1$ is a transmembrane protein expressed on $\mathrm{T}$ cells, B cells and Natural Killer (NK) cells. Interaction with its ligands, Programmed Cell Death Ligand-1 and 2 (PD-L1 and PD-L2) promotes T cell exhaustion and directly prevents apoptosis of tumour cells (5). PD-L1 is expressed in a variety of tissues, including tumours; overexpression of PD-L1 by tumour cells activates the PD-1 pathway binding to the PD-1 receptor. Subsequently, the PD-1 pathway blocks the immune response by downregulating $T$ cell effector functions (6). Antibodies against PD-1, such as pembrolizumab and nivolumab, and PD$\mathrm{L} 1$, such as durvalumab, block immune checkpoints from binding to their ligands, release the brakes and unleash T cells.

Immune checkpoint inhibitors, such as anti-CTLA-4 and anti-PD-1 antibodies have changed the landscape 
of advanced cancer treatment during the past few years. Despite important clinical benefits, they are associated with a wide spectrum of side effects termed immune-related adverse events (irAEs) that occur as a consequence of general immunological stimulation due to loss of $\mathrm{T}$ cell inhibition. These toxicities remain generally unknown to the broad oncology community and although they are generally manageable, severe irAEs can be life-threatening if not appropriately managed.

This review focuses on the description and management approach of irAEs associated with immune checkpoint inhibitors, with the view to alert the oncologist to their early identification and treatment.

\section{Clinical development of immune checkpoint inhibitors}

Ipilimumab is an anti-CTLA-4 monoclonal antibody that has been approved at a dose of $3 \mathrm{mg} / \mathrm{kg}$ for previously treated or chemo-naïve metastatic melanoma. It has been associated with a substantial survival advantage over cytotoxic chemotherapy in both pre-treated and treatment-naïve melanoma patients (7-8). In metastatic melanoma, combination immunotherapy with ipilimumab and anti-PD-1 monoclonal antibody nivolumab has demonstrated higher response rate and longer time to progression than either agent alone (9). In addition, ipilimumab improves recurrence-free survival in patients with resected stage III melanoma (10). On the other hand, ipilimumab has shown clinical activity in docetaxel-pretreated patients with prostate cancer who have received radiotherapy (11).

Nivolumab is a fully human IgG4 monoclonal antibody against PD-1. It has been approved as monotherapy or in combination with ipilimumab in the treatment of metastatic melanoma $(9,12)$. In addition, two phase III studies have shown superior overall survival with nivolumab compared to chemotherapy in patients with previously treated squamous and nonsquamous non-small cell lung cancer (NSCLC) (1314). Nivolumab has received FDA approval for both squamous and nonsquamous NSCLC. A phase III trial comparing nivolumab with chemotherapy in treatmentnaive NSCLC patients is ongoing (NCT02041533). On the other hand, nivolumab has shown important clinical activity in renal cell carcinoma (RCC). Based on a phase III study that demonstrated increased response rates, progression-free survival (PFS) and overall survival (OS) compared to everolimus in patients with previously treated RCC, it has been approved as a second line therapy by the FDA (15). Most recently, Checkmate-141 study has shown improvement in OS in patients with platinum refractory recurrent or metastatic squamous cell carcinoma of the head and neck (HNSCC) who were treated with nivolumab versus investigator's choice of therapy. Based on that study, FDA has granted a breakthrough therapy designation to nivolumab for the treatment of platinum refractory advanced HNSCC. Finally, nivolumab has been shown to be effective in hematological malignancies (16).

Pembrolizumab is a humanised monoclonal IgG4 anti-PD-1 antibody consisting of a high-affinity mouse anti-PD-1-derived variable region attached to a human IgG4 immunoglobulin molecule with an engineered Fc region for stabilisation (17). It has been found to be superior to ipilimumab in metastatic melanoma in the first line setting (18). Furthermore, it has been FDA approved as a second line therapy in patients with previously treated NSCLC and expression of PD-L1 (19). Pembrolizumab is currently being investigated in multiple clinical trials in a variety of malignancies, such as HNSCC and urothelial carcinoma and colorectal cancer with mismatch repair deficiency.

Atezolizumab is a monoclonal antibody against PD-L1. In 2016, FDA has granted priority review to Atezolizumab for the treatment of a) platinum refractory locally advanced or metastatic bladder cancer based on the phase II IMVigor 210 study, which showed a $15-25 \%$ response rate (ORR) in this setting and b) previously treated, PD-L1 expressing locally advanced or metastatic NSCLC, based on the Birch phase II study that demonstrated a $27 \%$ ORR. Tremelimumab is an anti-CTLA-4 antibody that has shown some activity in malignant mesothelioma, but failed to increase survival rates in the second/third line setting in the phase II DETERMINE trial. It is currently being investigated in a large number of clinical trials as monotherapy or in combination with anti-PD-L1 antibody durvalumab in multiple malignancies, such as HNSCC, gastric, breast, lung, renal cell and colorectal cancer.

\section{General approach to toxicity management}

Enhanced immune response driven by T-cell activation results in many autoimmunity-related side effects due to inflammation of normal tissues. Ipilimumab has a more severe toxicity profile, with grade $3 / 4$ toxicities occurring in $5-22 \%$ of patients in clinical trials $(7,20$ 21). The most common side effects reported in patients receiving ipilimumab are dermatological (rash, pruritus) or gastrointestinal (diarrhoea, colitis). It is important to underline that the toxicity of ipilimumab is dosedependent; frequency of adverse effects (AEs) increases 
at a $10 \mathrm{mg} / \mathrm{kg}$ dose (e.g. adjuvant setting in melanoma). Anti-PD-1 therapies are generally less toxic, with great $3 / 4$ events reported in approximately $5-11 \%$ of patients treated with nivolumab and $8-14 \%$ of patients treated with pembrolizumab $(12,22-24)$. Toxicity of nivolumab is not dose-dependent; on the other hand, the reported grade 3 to 4 AEs of the PD-1 antibody pembrolizumab seem to be somewhat higher at a dose of $10 \mathrm{mg} / \mathrm{kg}$ every 2 weeks than $2 \mathrm{mg} / \mathrm{kg}$ (the FDA-approved dose) or $10 \mathrm{mg} / \mathrm{kg}$ every 3 weeks (23). The most common AEs seen in patients receiving anti-PD-1 inhibitors are fatigue, rash, pruritus, diarrhoea, nausea, decreased appetite and arthralgia.(24-25).

The clinical team should conduct a thorough assessment of immune-mediated symptoms. Furthermore, education of patients and caregivers on the importance of detecting as well as prompt reporting of symptoms is crucial for timely recognition and appropriate management of irAEs. Education includes discussion of key points about immune-mediated AEs and importance of early medical intervention, as well as confirmation of patient's ability to verbalise important symptoms. It should be emphasised that symptoms may be intermittent and can occur weeks to months after treatment is completed. Consultation from other specialties might be also needed. General guidelines for the management of irAEs caused by ipilimumab are described in the FDA Risk Evaluation and Management Strategies (www.hcp.yervoy.com/pdf/rems-mangementguide.pdf). Although the side effects of anti-PD-1 monoclonal antibodies appear to be less severe than with those of ipilimumab, a similar approach is expected to apply to other immune checkpoint inhibitors.

In general, treatment of moderate or severe irAEs requires interruption of the drug and initiation of corticosteroids. For patients with grade 2 (moderate) immune-mediated toxicities, treatment with the checkpoint inhibitor should be withheld and should not be resumed until toxicity is grade 1 or less. If symptoms do not resolve within a week, corticosteroids (prednisone 0.5 $\mathrm{mg} / \mathrm{kg} /$ day or equivalent) should be started. On the other hand, for patients experiencing grade 3 or 4 (severe or life-threatening) irAEs, the drug should be permanently discontinued. High doses of corticosteroids (prednisone 1 to $2 \mathrm{mg} / \mathrm{kg} /$ day or equivalent) should be administered. When symptoms subside to grade 1 or less, steroids should be gradually tapered over at least one month. If symptoms do not recover, administration of infliximab (for gastrointestinal toxicity) or mycophenolate (in the case of hepatotoxicity) should be considered (20). In the majority of cases, toxicity of ipilimumab occurs early during the course of treatment, while pembrolizumab has a median onset of moderate to severe toxicity of approximately 9 weeks (26). Late-onset AEs might also develop (27).

\section{Immune checkpoint side effects and management}

\section{Diarrhoea and enterocolitis}

Diarrhoea is a common clinical complaint in patients treated with immune checkpoint inhibitors. Diarrhoea is clinically distinct from colitis, a definition that incorporates abdominal pain and endoscopic or radiographic findings of colonic inflammation. Diarrhoea and colitis most commonly occur within 6 weeks of treatment with ipilimumab and nivolumab and as late as 6 months after treatment with pembrolizumab (28-29). Both conditions should be differentially diagnosed from diarrhoea caused by Clostiridium difficile and other pathogens.

In a phase III melanoma trial, diarrhoea of any grade was reported in $30 \%$ of patients treated with ipilumumab; however, grade $3 / 4$ diarrhoea was observed in $10 \%$ of cases, defined as $\geq 7$ stools above baseline, fever, ileus or peritoneal signs (7). Similarly to other ipilimumab toxicities, diarrhoea is dose-dependent $(10 \%$ at a 10 $\mathrm{mg} / \mathrm{kg}$ dose vs. $1 \%$ at a $3 \mathrm{mg} / \mathrm{kg}$ dose) (30). On the other hand, colitis appears to be less common, with an incidence of approximately5\% in phase III trials (7). In those cases, endoscopic findings reveal mucosal edema with biopsies demonstrating neutrophilic, lymphocytic or mixed neutrophilic-lymphocytic infiltrates (31). CT scan findings associated with colitis caused by IPIs include mesenteric engorgement and bowel wall thickening (32). Diarrhoea/colitis appears to be less frequent with PD-1 blockade than with CTLA-4 blockade, with grade $3 / 4$ immune-mediated colitis seen in about 1 to $2 \%$ of cases $(12,24,33)$. Interestingly, patients who developed significant diarrhoea and colitis during CTLA-4 blockade have subsequently been treated with PD-1 antibodies without experiencing diarrhoea or colitis (34).

Maintenance of oral hydration is very important in patients treated with IPIs who develop diarrhoea. In patients with fewer than four stools per day over baseline (mild diarrhoea), administration of IPIs should be continued without initiation of corticosteroids. Specific diet and anti-motility agents, such as loperamide, can be helpful. Colonoscopy should be reserved for patients with $\geq$ grade 2 diarrhoea or in cases where diagnosis is unclear. If severe or life-threatening enterocolitis (grade $3 / 4$, increase of seven or more stools per day over baseline or other complications) develops, ipilimumab should be permanently discontinued and high dose IV corticosteroids (prednisone $1-2 \mathrm{mg} / \mathrm{kg}$ or equivalent) 
should be initiated (35-36). If symptoms do not resolve in three days, anti-TNF antibody infliximab at a dose of $5 \mathrm{mg} / \mathrm{kg}$ once every two weeks is recommended (37). In infliximab-refractory cases, mycophenylate mofetil can be used. In rare cases, colitis can result in perforation, requiring colostomy.

\section{Dermatological toxicity}

Dermatological toxicity is the most common and the earliest developed irAE, typically occurring within 3-4 weeks from treatment initiation (38). Delayed onset has been also reported (39). Clinical manifestations include maculopapular rash, pruritus and vitiligo. Approximately half of patients treated with ipilimumab will experience rash or pruritus; rashes are often mild in severity and present after the first or second dose (35). Rare cases of Steven-Johnson syndrome have been reported $(7,28)$. Combination immunotherapy was associated with the highest rate of severe skin toxicity (2.9\%) (9). Dermatological toxicity is observed in approximately 30 $40 \%$ of patients treated with anti-PD-1 therapies (40). Interestingly, skin toxicity mainly develops in patients with melanoma. For example, vitiligo has been reported in approximately $10 \%$ of patients with melanoma $(9,12)$, but has not been described in lung or renal cell studies $(13,15)$. Vitiligo has also been shown to be a predictive factor for durable response (41). Biopsy of rash usually reveals perivascular lymphocytic infiltrates extending deep into the dermis (42).

Grade 1 dermatological toxicity, defined by the Common Terminology Criteria for Adverse Events (CTCAE) as macular or papular eruption or erythema not associated with symptoms, is treated with topical corticosteroid ointments and does not require drug interruption. For patients with rash associated with pruritus or other symptoms and localised desquamation or other lesions covering $<50 \%$ of total body surface area (grade 2 toxicity), management is initially based on topical corticosteroids fro symptomatic relief; however, in contrast to grade 1 toxicity, ICls should be interrupted and systematic prednisolone at a dose of $0.5 \mathrm{mg} / \mathrm{kg}$ should be administered if symptoms do not recover within a week $(20,28)$. Grade 3/4 dermatological toxicity, defined as generalised rash with desquamation $>50 \%$ of total body surface area and bullous dermatitis, might require hospitalisation and dermatological consultation for skin biopsy. ICls should be permanently discontinued and intravenous administration of high dose corticosteroids $(1-2 \mathrm{mg} / \mathrm{kg})$ is the standard of care. Steroids should be tapered over one month following resolution of $A E$ to grade $1(20,28)$.

\section{Hepatotoxicity}

Hepatotoxicity is commonly manifested as asymptomatic elevation of aspartate aminotransferase (AST) and alanine aminotransferase (ALT) and is expected to occur within 8-12 weeks after initiation of treatment. Raise of total bilirubin is a rare consequence of prolonged periods of elevated hepatic enzymes (20). Hepatotoxicity has been observed with both antiCTLA-4 and anti-PD-1 inhibitors. In the pivotal phase III trial of ipilimumab in advanced melanoma, grade 2 hepatotoxicity was reported in $2.5 \%$ of patients and the incidence of 3-5 grade events was as high as $2 \%(7)$. In the large phase I studies of PD-1 blocking agents, grade $1 / 2$ liver dysfunction was reported in approximately $5 \%$ of patients and grade $3-5$ events were rare $(1 \%)$ (24). The incidence of hepatotoxicity is higher with the combination of ipilimumab and nivolumab, with grade $3 / 4$ events reaching $20 \%$ (9).

Hepatic function should be monitored prior to each dose of ipilimumab, nivolumab and pembrolizumab. Initial approach in the management of hepatotoxicity includes differential diagnosis from other causes of liver injury, such as medication, alcohol and viral hepatitis. Imaging studies should be performed to rule out metastatic disease. In the case of immune-related hepatitis, CT scan can show hepatomegaly and periportal edema (43).

If no other cause is identified, treatment with systemic corticosteroids should not be delayed (28). As immune-related hepatitis may persist, a minimum of three weeks' treatment with subsequent tapering of the dose is required. For grade 2 hepatotoxicity, defined as AST or ALT values, 2.5-5 times the upper limit of normal (ULN) and total bilirubin value 1.5-3 UPN, treatment with ICls should be withheld. Steroid therapy should continue until toxicity resolves to grade 0 or 1 . For grade 3/4 immune related hepatitis (AST/ALT values > 5 times the UPN and/or total bilirubin $>3$ times UPN) the drug should be permanently discontinued and liver biopsy might be considered. Hospitalisation is required if liver enzyme levels are >8 times UPN. In rare cases of corticosteroid refractory hepatitis, mecophenolate mofetil (500 mg every 12 hours) should be given (20, 28). Of note, infliximab should not be administered, since it carries a risk of hepatotoxicity.

\section{Endocrinopathies}

Endocrine toxicity occurs as a result of inflammation of the pituitary gland, thyroid and adrenal glands following therapy with ICls. It presents with non-specific 
symptoms, such as headache, fatigue and nausea. Median onset is approximately 7 weeks for ipilimumab and 10 weeks for nivolumab $(20,26)$. Clinically significant endocrinopathies typically occur in less than $5 \%$ of patients treated with ipilimumab; for anti-PD-1 therapies, grade 3/4 events are rarer (approximately 1\%) (44-45).

Pituitary dysfunction (hypophysitis) has been associated with $\mathrm{ICl}$ treatment in patients with various malignancies. Large differences (0-25\%) in the incidence of ipililimumab-induced hypophysitis have been reported among different trials (46). In the landmark phase III trial of ipilimumab, severe hypophysitis has been reported in $1.8 \%$ of patients (7). Tremelimumab has been much less frequently related to hypophysitis (0.5-4\%) (47); similarly, hypophysitis is a rare event in patients treated with anti-PD-1 antibodies $(18,33)$. Median time to onset is approximately $2-4$ months within initiation of treatment (48), although delayed presentations might also occur (49).

Hypophysitis presents with non-specific symptoms, such as headache and fatigue. Diagnosis is based on low levels of hormones produced by the pituitary [adrenocorticotropic hormone (ACTH), follicle stimulating hormone $(\mathrm{FSH})$, thyroid-stimulating hormone (TSH), luteinizing hormone (LH) and growth hormone $(\mathrm{GH})$ ]; differential diagnosis includes primary hypothyroidism (low thyroxine, high TSH) and primary adrenal insufficiency (low cortisol). Imaging typically reveals enhancement or swelling of the pituitary gland (50). For >grade 2 toxicity, treatment with $\mathrm{ICI}$ should be interrupted and high-dose corticosteroids should be initiated (prednisone $1 \mathrm{mg} / \mathrm{kg}$ daily). Permanent discontinuation of the drug is recommended in grade 3/4 toxicity. Endocrinology consultation and long-term supplementation of affected hormones due to secondary hypothyroidism and hypoadrenalism is necessary (28).

Autoimmune thyroid disease can be manifested either as primary hypothyroidism due to destructive thyroiditis or as hyperthyroidism as a result of Grave's disease (28). Hypothyroidism is more common with antiPD-1 therapies than with ipilimumab $3 \mathrm{mg} / \mathrm{kg}(9,18,33)$, although a higher incidence can be seen with ipilimumab at an increased dose (10 mg/kg) (10). Hypothyroidism is usually subclinical; hormone replace therapy with levothyroxine can be initiated and $\mathrm{ICI}$ treatment can be continued without interruption. If concurrent hypophysitis is suspected (low TSH, low T4), treatment should not be solely based on TSH measurement and free thryxoxine and T3 levels should also be taken into account (44). On the other hand, hyperthyroidism is less common and might be a result of transient thyroiditis preceding hypothyroidism or TSH-receptor antibodies and Grave's disease (26). Persistent hyperthyroidism should be treated as primary hyperthyroidism.

In clinical trials with ICls, primary adrenal insufficiency has been reported in $1.5-2 \%$ of patients (44). It should be distinguished from hypophysitis based on measurement of ACT levels. Acute adrenal insufficiency (adrenal crisis) constitutes an emergency manifested as dehydration, hypotension, hyperkalemia and hyponatremia. Patients suspected to have adrenal crisis should be immediately admitted to the hospital ward with prompt initiation of IV corticosteroids (20). Endocrinology consultation is also warranted.

Other endocrinopathies include type I diabetes mellitus, which can occur with both anti-CTLA-4 and anti-PD-1 blockade at a rate of approximately <1\% (44). Incidence is doubled with the use of combined ipilimumab and nivolumab (9). Insulin treatment is recommended. Finally, cases of low testosterone have been reported in patients treated with ipilimumab (49).

\section{Immune-mediated pneumonitis}

Pneumonitis is an uncommon side effect of patients treated with ICls and can occur with both anti-CTLA-4 and anti-PD-1 blockade. Ipilimumab-induced pneumonitis has been reported in up to $5 \%$ of patients treated with ipilimumab monotherapy $(12,33)$; combination of nivolumab and ipilimumab results in pneumonitis at a higher incidence (5-10\%, with $2 \%$ grade $3-4)$ (9). Pneumonitis can occur in 2-5\% of patients treated with nivolumab, more commonly in patients with renal cell and lung cancer than in patients with melanoma (14, 19, 33). Implicated mechanisms are still undetermined, although it is hypothesised that dysregylated effector $\mathrm{T}$ cells are accumulated in pulmonary interstitium, leading to increased inflammatory response (51). In any patient presenting with symptoms of upper respiratory infection, cough or shortness of breath, pneumonitis should be ruled out with appropriate imaging. Bronchoscopy is also recommended to exclude infectious diseases before the initiation of immunosuppression. For grade 2 pneumonitis, $\mathrm{ICl}$ treatment should be interrupted and IV corticosteroids should be started at a dose of $1 \mathrm{mg} /$ $\mathrm{kg}$ daily. For more severe cases, management includes hospitalisation, high-dose corticosteroids (2-4 mg/kg/day) and permanent discontinuation of $\mathrm{ICl}$ treatment (35).

\section{Renal injury}

Renal insufficiency has been reported with both antiCTLA-4 and anti-PD-1 blockade, at a relatively low incidence (0-4\%) (26). The highest incidence reported was in the phase II trial with nivolumab in NSCLC 
Table 1. Management of immune-related adverse events.

\begin{tabular}{|c|c|c|c|c|}
\hline Grade & Grade 1 & Grade 2 & Grade 3 & Grade 4 \\
\hline $\begin{array}{l}\text { Diarrhoea- } \\
\text { Enterocolitis }\end{array}$ & $\begin{array}{l}\text { No ICl interruption } \\
\text { Hydration } \\
\text { Specific diet, } \\
\text { loperamide }\end{array}$ & $\begin{array}{l}\text { Withhold } \mathrm{ICl} \text {. } \\
\text { As grade } 1 \text { if patient well. } \\
\text { If no improvement in } 5 \text { days/ } \\
\text { worsening of symptoms start } \\
\text { prednisone } 0.5-1 \mathrm{mg} / \mathrm{kg} \\
\text { (tapering over } 2-4 \text { weeks). } \\
\text { If no improvement with steroids, } \\
\text { manage as per grade } 3 \text {. } \\
\text { Consider colonoscopy. }\end{array}$ & $\begin{array}{l}\text { Permanently discontinue } \mathrm{ICl} \text {. } \\
\text { Hospitalisation required. } \\
\text { Start prednisone } 1-2 \mathrm{mg} / \mathrm{kg} \text {. If no } \\
\text { improvement in } 2-3 \text { days, start } \\
\text { infliximab } 5 \mathrm{mg} / \mathrm{kg} \text { (if no sepsis/ } \\
\text { perforation) with synchronous } \\
\text { administration of steroids. Once } \\
\text { resolved to grade } 1 \text {, taper steroids over } \\
\text { minimum one month. } \\
\text { In infliximab-refractory cases, } \\
\text { mycophenylate mofetil can be used. } \\
\text { Colonoscopy recommended. }\end{array}$ & $\begin{array}{l}\text { Permanently } \\
\text { discontinue ICl. } \\
\text { As per grade } 3 \text {. } \\
\text { Gastrenterologist and } \\
\text { surgeon consultation } \\
\text { recommended. }\end{array}$ \\
\hline $\begin{array}{l}\text { Dermatological } \\
\text { toxicity }\end{array}$ & $\begin{array}{l}\text { No ICl interruption. } \\
\text { Topical } \\
\text { corticosteroid } \\
\text { ointments }\end{array}$ & $\begin{array}{l}\text { Withhold ICl. } \\
\text { Initially manage with topical } \\
\text { corticosteroid ointments. } \\
\text { If no improvement in one week, } \\
\text { start IV prednisone } 0.5 \mathrm{mg} / \mathrm{kg} \text {. } \\
\text { Restart treatment once toxicity } \\
\text { resolves to grade } 1 .\end{array}$ & $\begin{array}{l}\text { Permanently discontinue } \mathrm{ICl} \text {. } \\
\text { Start prednisone } 1-2 \mathrm{mg} / \mathrm{kg} \text {. } \\
\text { Skin biopsy and dermatological } \\
\text { consultation recommended. } \\
\text { Hospitalisation might be required. }\end{array}$ & $\begin{array}{l}\text { Permanently } \\
\text { discontinue ICl. } \\
\text { Manage as per } \\
\text { grade } 3 . \\
\text { Hospitalisation } \\
\text { required. }\end{array}$ \\
\hline Hepatotoxicity & $\begin{array}{l}\text { No ICl interruption. } \\
\text { Check for other } \\
\text { causes. }\end{array}$ & $\begin{array}{l}\text { Withhold } \mathrm{ICl} \text {. } \\
\text { Start prednisone } 1-2 \mathrm{mg} / \mathrm{kg} \text {. } \\
\text { Continue until toxicity resolves to } \\
\text { grade } 1 . \\
\text { Tapering over } 1 \text { month. }\end{array}$ & $\begin{array}{l}\text { Permanently discontinue ICl. } \\
\text { Start prednisone } 1-2 \mathrm{mg} / \mathrm{kg} \text {. Continue } \\
\text { until toxicity resolves to grade } 1 . \\
\text { In rare cases of corticosteroid refractory } \\
\text { hepatitis, mecophenolate mofetil ( } 500 \\
\text { mg every } 12 \text { hours) should be given. } \\
\text { Consider liver biopsy. } \\
\text { Hospitalisation if liver enzyme levels } \\
>8 \text { UPN }\end{array}$ & $\begin{array}{l}\text { Permanently } \\
\text { discontinue } \mathrm{ICl} \text {. } \\
\text { As per grade } 3 \text {. }\end{array}$ \\
\hline Hypophysitis & $\begin{array}{l}\text { No } \mathrm{ICl} \text { interruption. } \\
\text { Endocrinology } \\
\text { consultation } \\
\text { for hormone } \\
\text { replacement. }\end{array}$ & $\begin{array}{l}\text { Withhold } \mathrm{ICl} . \\
\text { Start prednisone } 1 \mathrm{mg} / \mathrm{kg} \text {. } \\
\text { Endocrinology consultation for } \\
\text { hormone replacement. }\end{array}$ & $\begin{array}{l}\text { Permanently discontinue } \mathrm{ICI} \text {. Start } \\
\text { prednisone } 1-2 \mathrm{mg} / \mathrm{kg} \text {. } \\
\text { Endocrinology consultation for hormone } \\
\text { replacement. }\end{array}$ & $\begin{array}{l}\text { Permanently } \\
\text { discontinue } \mathrm{ICl} \text {. } \\
\text { As per grade } 3 \text {. }\end{array}$ \\
\hline Hypothyroidism & $\begin{array}{l}\text { No ICl interruption. } \\
\text { Monitor. }\end{array}$ & $\begin{array}{l}\text { No ICl interruption. } \\
\text { Start levothyroxine. }\end{array}$ & $\begin{array}{l}\text { Start prednisone } 1-2 \mathrm{mg} / \mathrm{kg} \text {. } \\
\text { Hospitalisation and endocrinology } \\
\text { consultation recommended. }\end{array}$ & As per grade 3 . \\
\hline Hyperthyroidism & $\begin{array}{l}\text { No ICl interruption. } \\
\text { Monitor. }\end{array}$ & $\begin{array}{l}\text { Endocrinology consultation. } \\
\text { Propranolol for symptoms. } \\
\text { Steroids or carbimazole might } \\
\text { be needed. }\end{array}$ & $\begin{array}{l}\text { Start prednisone } 1-2 \mathrm{mg} / \mathrm{kg} \text {. } \\
\text { Hospitalisation and endocrinology } \\
\text { consultation recommended. }\end{array}$ & As per grade 3 . \\
\hline Pneumonitis & $\begin{array}{l}\text { Delay drug } \\
\text { administration. } \\
\text { Exclude other } \\
\text { causes. } \\
\text { Monitoring and } \\
\text { management } \\
\text { reassessment. }\end{array}$ & $\begin{array}{l}\text { Withhold ICl. } \\
\text { Start prednisone } 1-2 \mathrm{mg} / \mathrm{kg} \text {. } \\
\text { Consider hospitalisation. } \\
\text { Consider empiric antibiotics. } \\
\text { Taper steroids if improvement } \\
\text { noticed. } \\
\text { If no improvement, treat as } \\
\text { grade } 3 \text {. }\end{array}$ & $\begin{array}{l}\text { Permanently discontinue ICl. } \\
\text { Hospitalisation required. } \\
\text { Exclude other causes (bronchoscopy). } \\
\text { Add antibiotics for opportunistic } \\
\text { infections. } \\
\text { If no improvement, add infliximab. } \\
\text { If improvement, taper steroids. }\end{array}$ & $\begin{array}{l}\text { Permanently } \\
\text { discontinue ICI. } \\
\text { As per grade } 3 \text {. } \\
\text { Consider admission } \\
\text { to ITU. }\end{array}$ \\
\hline Renal injury & $\begin{array}{l}\text { No ICl interruption. } \\
\text { Exclude other } \\
\text { causes. } \\
\text { Monitoring. }\end{array}$ & $\begin{array}{l}\text { Withhold ICl. } \\
\text { Exclude other causes. } \\
\text { Start prednisone } 0.5-1 \mathrm{mg} / \mathrm{kg} \text {. } \\
\text { If no improvement, manage as } \\
\text { per grade } 3 \text {. }\end{array}$ & $\begin{array}{l}\text { Permanently discontinue ICl. } \\
\text { Start prednisone } 1-2 \mathrm{mg} / \mathrm{kg} \text {. } \\
\text { Consider renal biopsy. }\end{array}$ & As per grade 3 . \\
\hline
\end{tabular}

$I C I=$ immune checkpoint inhibitors, ITU=intensive care unit.

(52). Histopathological findings of CTLA-4-induced nephrotoxicity include acute granulomatous interstitial nephritis and lupus membranous nephropathy (53-54). Treatment with oral or intravenous corticosteroids has been associated with improvement in renal function (55).

\section{Other immune-related AEs}

Treatment with ipilimumab can result in ocular toxicity, such as episcleretis, conjunctivitis and uveitis at an incidence of $1 \%$. Associated symptoms include 
photophobia, pain and eye dryness (56). Ophthalmology consultation is warranted.

A number of neurological toxicities have been also reported with ipilimumab, such as Guillain-Barre syndrome (57). In addition, asymptomatic laboratory elevation of amylase and lipase that does not fulfil the criteria of acute pancreatitis is a common finding, and its clinical significance is unknown $(7,12)$. Red cell aplasia, neutropenia, thrombocytopenia, and acquired hemophilia $A$ have been described in patients treated with ipilimumab (58-59).

\section{Discussion and future directions}

Treatment with ICls has dramatically changed the landscape of advanced cancer treatment in the past few years, albeit at the expense of immune-related side effects. Ir-AEs are usually manageable and reversible with early recognition and specialised management; however, they can result in severe consequences in certain cases. Due to their unique mechanism of action, toxicities caused by $\mathrm{ICls}$ are different from those exerted by conventional chemotherapy. Therefore, physicians might encounter toxicities that they are not familiar with. It is important to note that onset of irAEs may be insidious. Careful education and awareness of the clinical team is crucial for early initiation of appropriate immunosuppressive treatment.

Ipilimumab is relatively toxic; on the contrary, newer anti-PD-1 immunotherapies are more tolerable (grade $3 / 4$ AEs $20-30 \%$ versus $10-15 \%$ ). As expected, the combination of ipilimumab and nivolumab that has been approved for the treatment of advanced melanoma has yielded the highest incidence of irAEs (grade 3/4 AEs $55 \%$ ) (9). ICls differ in the frequency of AEs and this might guide appropriate selection of patients based

\section{References}

[1] Finn OJ. Immuno-oncology: understanding the function and dysfunction of the immune system in cancer. Ann Oncol. 2012 Sep;23 Suppl 8:viii6-9.

[2] EggermontA, Finn O.Advances in immuno-oncology. Foreword. Ann Oncol. 2012 Sep;23 Suppl 8:viii5.

[3] Lesterhuis WJ, Haanen JB, Punt CJ. Cancer immunotherapy--revisited. Nat Rev Drug Discov. 2011 Aug;10(8):591-600.

[4] Linsley PS, Brady W, Urnes M, Grosmaire LS, Damle NK, Ledbetter JA. CTLA-4 is a second receptor for the $B$ cell activation antigen B7. J Exp Med. 1991 Sep 1;174(3):561-9. on toxicity profile. Autoimmune thyroid dysfunction, rash and vitiligo are more common with nivolumab and pembrolizumab, whereas diarrhoea and hypophysitis occur more commonly in patients treated with ipilimumab $(8,12,18,23)$.

Some interesting points are worth mentioning. First, ipilimumab irAEs are dose-dependent. In the adjuvant melanoma trial, where ipilimumab was administered at a dose of $10 \mathrm{mg} / \mathrm{kg}$, grade $3 / 4$ irAEs occurred in approximately $40 \%$ of patients, compared to $20-27 \%$ of grade $3 / 4$ events with ipilimumab at a dose of $3 \mathrm{mg} / \mathrm{kg}$ (10). On the contrary, toxicities of anti-PD-1 antibodies are not dose-dependent. Second, several ir-AEs are more common in certain tumour types. For example, pulmonary toxicity is more common in lung cancer, possibly related to an underlying inflammation due to smoking (51). In addition, skin toxicity occurs more frequently in melanoma patients.

Development of irAEs has been associated with improved outcomes in some retrospective studies. A study involving patients treated with ipilimumab found that highest response rates were seen in patients with grade 3-4 toxicities (60). Use of steroids does not appear to have a detrimental effect on the clinical course of the disease. In a recent study, patients treated with nivolumab who experienced any AE had a better response, although outcomes were worse in patients with grade $3 / 4$ toxicity (61).

The introduction of anti-CTLA-4 and anti-PD-1 immunotherapies has improved survival in patients with melanoma, lung and renal cell cancer. A large number of ongoing trials are evaluating $\mathrm{ICls}$ in a variety of malignancies. As treatment with ICls gradually becomes a necessity, it is imperative that the clinical team and physicians are educated and familiar with irAEs and their management.
[5] Dolan DE, Gupta S. PD-1 pathway inhibitors: changing the landscape of cancer immunotherapy. Cancer Control. 2014 Jul;21(3):231-7.

[6] Sznol M, Chen L. Antagonist antibodies to PD-1 and B7-H1 (PD-L1) in the treatment of advanced human cancer--response. Clin Cancer Res. 2013 Oct 1;19(19):5542

[7] Hodi FS, O'Day SJ, McDermott DF, Weber RW, Sosman JA, Haanen JB, et al. Improved survival with ipilimumab in patients with metastatic melanoma. $\mathrm{N}$ Engl J Med. 2010 Aug 19;363(8):711-23. 
[8] Robert C, Thomas L, Bondarenko I, O'Day S, Weber J, Garbe C, et al. Ipilimumab plus dacarbazine for previously untreated metastatic melanoma. $\mathrm{N}$ Engl J Med. 2011 Jun 30;364(26):2517-26.

[9] Larkin J, Chiarion-Sileni V, Gonzalez R, Grob JJ, Cowey CL, Lao CD, et al. Combined Nivolumab and Ipilimumab or Monotherapy in Untreated Melanoma. N Engl J Med. 2015 Jul 2;373(1):23-34.

[10] Eggermont AM, Chiarion-Sileni V, Grob JJ, Dummer R, Wolchok JD, Schmidt H, et al. Adjuvant ipilimumab versus placebo after complete resection of high-risk stage III melanoma (EORTC 18071): a randomised, double-blind, phase 3 trial. Lancet Oncol. 2015 May;16(5):522-30.

[11] Kwon ED, Drake CG, Scher HI, Fizazi K, Bossi $A$, van den Eertwegh AJ, et al. Ipilimumab versus placebo after radiotherapy in patients with metastatic castration-resistant prostate cancer that had progressed after docetaxel chemotherapy (CA184043): a multicentre, randomised, double-blind, phase 3 trial. Lancet Oncol. 2014 Jun;15(7):70012.

[12] Robert C, Long GV, Brady B, Dutriaux C, Maio M, Mortier L, et al. Nivolumab in previously untreated melanoma without BRAF mutation. N Engl J Med. 2015 Jan 22;372(4):320-30.

[13] Brahmer J, Reckamp KL, Baas P, Crino L, Eberhardt WE, Poddubskaya E, et al. Nivolumab versus Docetaxel in Advanced Squamous-Cell Non-Small-Cell Lung Cancer. N Engl J Med. 2015 Jul 9;373(2):123-35.

[14] Borghaei H, Paz-Ares L, Horn L, Spigel DR, Steins M, Ready NE, et al. Nivolumab versus Docetaxel in Advanced Nonsquamous Non-Small-Cell Lung Cancer. N Engl J Med. 2015 Oct 22;373(17):162739.

[15] Motzer RJ, Escudier B, McDermott DF, George S, Hammers HJ, Srinivas $S$, et al. Nivolumab versus Everolimus in Advanced Renal-Cell Carcinoma. N Engl J Med. 2015 Nov 5;373(19):1803-13.

[16] Ansell SM, Lesokhin AM, Borrello I, Halwani A, Scott EC, Gutierrez M, et al. PD-1 blockade with nivolumab in relapsed or refractory Hodgkin's lymphoma. N Engl J Med. 2015 Jan 22;372(4):311-9.

[17] Philips GK, Atkins M. Therapeutic uses of antiPD-1 and anti-PD-L1 antibodies. Int Immunol. 2015 Jan;27(1):39-46.

[18] Robert C, Schachter J, Long GV, Arance A, Grob JJ, Mortier L, et al. Pembrolizumab versus Ipilimumab in Advanced Melanoma. N Engl J Med. 2015 Jun 25;372(26):2521-32.

[19] Herbst RS, Baas P, Kim DW, Felip E, Perez-Gracia JL, Han JY, et al. Pembrolizumab versus docetaxel for previously treated, PD-L1-positive, advanced non-small-cell lung cancer (KEYNOTE-010): a randomised controlled trial. Lancet. $2015 \mathrm{Dec} 18$.

[20] Weber JS, Kahler KC, Hauschild A. Management of immune-related adverse events and kinetics of response with ipilimumab. J Clin Oncol. 2012 Jul 20;30(21):2691-7.

[21] O'Day SJ, Maio M, Chiarion-Sileni V, Gajewski TF, Pehamberger $\mathrm{H}$, Bondarenko IN, et al. Efficacy and safety of ipilimumab monotherapy in patients with pretreated advanced melanoma: a multicenter single-arm phase II study. Ann Oncol. 2010 Aug;21(8):1712-7.

[22] Topalian SL, Hodi FS, Brahmer JR, Gettinger SN, Smith DC, McDermott DF, et al. Safety, activity, and immune correlates of anti-PD-1 antibody in cancer. N Engl J Med. 2012 Jun 28;366(26):2443-54.

[23] Ribas A, Puzanov I, Dummer R, Schadendorf D, Hamid O, Robert C, et al. Pembrolizumab versus investigator-choice chemotherapy for ipilimumab-refractory melanoma (KEYNOTE-002): a randomised, controlled, phase 2 trial. Lancet Oncol. 2015 Aug;16(8):908-18.

[24] Robert C, Ribas A, Wolchok JD, Hodi FS, Hamid O, Kefford R, et al. Anti-programmed-death-receptor-1 treatment with pembrolizumab in ipilimumabrefractory advanced melanoma: a randomised dose-comparison cohort of a phase 1 trial. Lancet. 2014 Sep 20;384(9948):1109-17.

[25] Topalian SL, Sznol M, McDermott DF, Kluger HM, Carvajal RD, Sharfman WH, et al. Survival, durable tumor remission, and long-term safety in patients with advanced melanoma receiving nivolumab. J Clin Oncol. 2014 Apr 1;32(10):1020-30.

[26] Spain L, Diem S, Larkin J. Management of toxicities of immune checkpoint inhibitors. Cancer Treat Rev. 2016 Mar;44:51-60.

[27] Johnson DB, Friedman DL, Berry E, Decker I, Ye $\mathrm{F}$, Zhao S, et al. Survivorship in Immune Therapy: Assessing Chronic Immune Toxicities, Health Outcomes, and Functional Status among Long-term Ipilimumab Survivors at a Single Referral Center. Cancer Immunol Res. 2015 May;3(5):464-9.

[28] Squibb BM. Yervoy (Ipilimumab) Product Information, 2015.

[29] Merck Sharp \& Dohme Corp. Keytruda (Pembrolizumab) Product Information, 2015.

[30] Wolchok JD, Weber JS, Hamid O, Lebbe C, Maio $M$, Schadendorf $D$, et al. Ipilimumab efficacy and safety in patients with advanced melanoma: a retrospective analysis of HLA subtype from four trials. Cancer Immun. 2010;10:9. 
[31] Berman D, Parker SM, Siegel J, Chasalow SD, Weber J, Galbraith S, et al. Blockade of cytotoxic T-lymphocyte antigen-4 by ipilimumab results in dysregulation of gastrointestinal immunity in patients with advanced melanoma. Cancer Immun. 2010;10:11.

[32] Kim KW, Ramaiya NH, Krajewski KM, Shinagare AB, Howard SA, Jagannathan JP, et al. Ipilimumabassociated colitis: CT findings. AJR Am J Roentgenol. 2013 May;200(5):W468-74.

[33] Weber JS, D'Angelo SP, Minor D, Hodi FS, Gutzmer $R$, Neyns B, et al. Nivolumab versus chemotherapy in patients with advanced melanoma who progressed after anti-CTLA-4 treatment (CheckMate 037): a randomised, controlled, open-label, phase 3 trial. Lancet Oncol. 2015 Apr;16(4):375-84.

[34] Weber JS, Kudchadkar RR, Yu B, Gallenstein D, Horak CE, Inzunza HD, et al. Safety, efficacy, and biomarkers of nivolumab with vaccine in ipilimumabrefractory or -naive melanoma. J Clin Oncol. 2013 Dec 1;31(34):4311-8.

[35] Villadolid J, Amin A. Immune checkpoint inhibitors in clinical practice: update on management of immune-related toxicities. Transl Lung Cancer Res. 2015 Oct;4(5):560-75.

[36] Fecher LA, Agarwala SS, Hodi FS, Weber JS. Ipilimumab and its toxicities: a multidisciplinary approach. Oncologist. 2013 Jun;18(6):733-43.

[37] Minor DR, Chin K, Kashani-Sabet M. Infliximab in the treatment of anti-CTLA4 antibody (ipilimumab) induced immune-related colitis. Cancer Biother Radiopharm. 2009 Jun;24(3):321-5.

[38] Weber JS. Practical management of immunerelated adverse events from immune checkpoint protein antibodies for the oncologist. Am Soc Clin Oncol Educ Book. 2012:174-7.

[39] Ludlow SP, Kay N. Delayed dermatologic hypersensitivity reaction secondary to ipilimumab. J Immunother. 2015 May;38(4):165-6.

[40] Naidoo J, Page DB, Li BT, Connell LC, Schindler $\mathrm{K}$, Lacouture ME, et al. Toxicities of the anti-PD-1 and anti-PD-L1 immune checkpoint antibodies. Ann Oncol. 2016 Apr 12.

[41] Hua C, Boussemart L, Mateus C, Routier E, Boutros C, Cazenave H, et al. Association of Vitiligo With Tumor Response in Patients With Metastatic Melanoma Treated With Pembrolizumab. JAMA Dermatol. 2016 Jan;152(1):45-51.

[42] Hodi FS, Minm MC, Soiffer RJ, Haluska FG, Butler M, Seiden MV, et al. Biologic activity of cytotoxic $T$ lymphocyte-associated antigen 4 antibody blockade in previously vaccinated metastatic melanoma and ovarian carcinoma patients. Proc Natl Acad Sci U S A. 2003 Apr 15;100(8):4712-7.

[43] Kim KW, Ramaiya NH, Krajewski KM, Jagannathan JP, Tirumani SH, Srivastava A, et al. Ipilimumab associated hepatitis: imaging and clinicopathologic findings. Invest New Drugs. 2013 Aug;31(4):1071-7.

[44] Corsello SM, Barnabei A, Marchetti P, De Vecchis $L$, Salvatori R, Torino F. Endocrine side effects induced by immune checkpoint inhibitors. J Clin Endocrinol Metab. 2013 Apr;98(4):1361-75.

[45] Corsello SM, Salvatori R, Barnabei A, De Vecchis L, Marchetti P, Torino F. Ipilimumab-induced endocrinopathies: when to start corticosteroids (or not). Cancer Chemother Pharmacol. 2013 Aug;72(2):489-90.

[46] Torino F, Corsello SM, Salvatori R. Endocrinological side-effects of immune checkpoint inhibitors. Curr Opin Oncol. 2016 Apr 28.

[47] Ribas A, Kefford R, Marshall MA, Punt CJ, Haanen $\mathrm{JB}$, Marmol $\mathrm{M}$, et al. Phase III randomized clinical trial comparing tremelimumab with standard-of-care chemotherapy in patients with advanced melanoma. J Clin Oncol. 2013 Feb 10;31(5):616-22.

[48] Weber JS, Yang JC, Atkins MB, Disis ML. Toxicities of Immunotherapy for the Practitioner. J Clin Oncol. 2015 Jun 20;33(18):2092-9.

[49] Ryder M, Callahan M, Postow MA, Wolchok J, Fagin JA. Endocrine-related adverse events following ipilimumab in patients with advanced melanoma: a comprehensive retrospective review from a single institution. Endocr Relat Cancer. 2014 Apr;21(2):371-81.

[50] Dillard T, Yedinak CG, Alumkal J, Fleseriu M. AntiCTLA-4 antibody therapy associated autoimmune hypophysitis: serious immune related adverse events across a spectrum of cancer subtypes. Pituitary. 2010;13(1):29-38.

[51] Tabchi S, Messier C, Blais N. Immune-mediated respiratory adverse events of checkpoint inhibitors. Curr Opin Oncol. 2016 Jun 30.

[52] Rizvi NA, Mazieres J, Planchard D, Stinchcombe TE, Dy GK, Antonia SJ, et al. Activity and safety of nivolumab, an anti-PD-1 immune checkpoint inhibitor, for patients with advanced, refractory squamous non-small-cell lung cancer (CheckMate 063): a phase 2, single-arm trial. Lancet Oncol. 2015 Mar;16(3):257-65.

[53] Izzedine H, Gueutin V, Gharbi C, Mateus C, Robert $C$, Routier $E$, et al. Kidney injuries related to ipilimumab. Invest New Drugs. 2014 Aug;32(4):76973. 
[54] Fadel F, El Karoui K, Knebelmann B. Anti-CTLA4 antibody-induced lupus nephritis. N Engl J Med. 2009 Jul 9;361(2):211-2.

[55] Voskens CJ, Goldinger SM, Loquai C, Robert C, Kaehler KC, Berking C, et al. The price of tumor control: an analysis of rare side effects of antiCTLA-4 therapy in metastatic melanoma from the ipilimumab network. PLoS One. 2013;8(1):e53745.

[56] Robinson MR, Chan CC, Yang JC, Rubin BI, Gracia GJ, Sen HN, et al. Cytotoxic T lymphocyteassociated antigen 4 blockade in patients with metastatic melanoma: a new cause of uveitis. J Immunother. 2004 Nov-Dec;27(6):478-9.

[57] Wilgenhof S, Neyns B. Anti-CTLA-4 antibodyinduced Guillain-Barre syndrome in a melanoma patient. Ann Oncol. 2011 Apr;22(4):991-3.

[58] Akhtari M, Waller EK, Jaye DL, Lawson DH, Ibrahim $\mathrm{R}$, Papadopoulos NE, et al. Neutropenia in a patient treated with ipilimumab (anti-CTLA-4 antibody). J Immunother. 2009 Apr;32(3):322-4.
[59] Gordon IO, Wade T, Chin K, Dickstein J, Gajewski TF. Immune-mediated red cell aplasia after anti-CTLA-4 immunotherapy for metastatic melanoma. Cancer Immunol Immunother. 2009 Aug;58(8):1351-3.

[60] Downey SG, Klapper JA, Smith FO, Yang JC, Sherry RM, Royal RE, et al. Prognostic factors related to clinical response in patients with metastatic melanoma treated by CTL-associated antigen-4 blockade. Clin Cancer Res. 2007 Nov 15;13(22 Pt 1):6681-8.

[61] Weber J AS, Topalian SL, Schadendorf D, Larkin J, Sznol M, Liu HY, Waxman I, Robert C. Safety profile of nivolumab (NIVO) in patients (pts) with advanced melanoma (MEL): A pooled analysis. J Clin Oncol 33, 2015 (suppl; abstr 9018). 